\title{
INFLUENCE OF ACCULTURATION ON THE BRAND SELECTION OF THE SOUTH ASIAN DIASPORA IN THE UK
}

\author{
Muhammad Rizwan ${ }^{1}$ \\ Institute of Management Sciences, Bahauddin Zakariya University \\ Muhammad Hassan ${ }^{2}$ \\ Institute of Management Sciences, Bahauddin Zakariya University (Corrosponding Author) \\ Umme Kalsoom ${ }^{3}$ \\ Anglia Ruskin University, $U K$
}

\begin{abstract}
It is found throughout the literature that culture is an important influence on consumer behaviour. Those people who migrate to another country belong to a different class of consumers, who is influenced by home or host culture simultenously. This study is aimed to explore the influence of acculturation on the brand choice of the South Asian immigrants in the UK. This study used a quantitative methodology to test a proposed model, developed with the help of past studies. A survey instrument was developed to collect data from the South Asian immigrant population living in the UK. Structural equation modelling was used to test the hypotheses. The study found that various personal factors like length of stay in the UK and income positively influence the acculturation, while acculturation decreasing with the increasing age among the South Asians in the UK.This study provides an insight about looking beyond the demographic variables while developing strategies to attract the market segments. The brand marketing management in the UK and other western countries while attracting the diaspora should understand the level of acculturation of their target market. The retailers may also conider the consumer cultural profile while deciding ther product mix.
\end{abstract}

Key words: Consumer Behaviour, Acculturation, Minority Consumers, Brand Choice, South Asian Diaspora

Jel classification:D11, D12,D13

Thematerialpresentedbytheauthordoesnotnecessarilyportraytheviewpointoftheeditors andthemanagementoftheILMA University formerly (IBT)

\footnotetext{
${ }^{1}$ Muhammad:

Rizwan:mriz@hotmail.com

${ }^{2}$ Muhammad:

Hassan:muhammadhassan@gmail.com

${ }^{3}$ Umme Kalsoom:

ummekalsoom@gmail.com
} 


\section{INTRODUCTION}

This research aims at exploring the consumer behaviour of the South Asian immigrants in the UK. People from former British India have a long history of migrating to the Great Britain since the colonial times. There are many studies about these ethnic minorities regarding acculturation of ethnic minorities and Marketing to these minorities, (Burton 2000; Jamal, 2003), some focused on internal processes and perception of ethnic consumers (Deshpande, et al., 1986, Lindridge 2010); some studies were focusing buying behaviour of ethnic consumers inthe purchase and consumption of various product categories (Ogden, Ogden, and Schau, 2004, Armstrong and Haiss, 2007, Mokhlis, et al., 2010). This studies emphasis on attitude and behaviour of ethnic consumers towards buying and consuming a product. A product is more than the set of physical attributes, brand and the brand image are the important intangible components of products. It is argued that the brand image strongly influences the brand choice (Jobber and Ellis-Chadwick 2012, p.302). The ethnic minority consumers in the diaspora settings are exposed to both ethnic and mainstream brands. There is a dearth of knowledge explaining the choice of brands of ethnic minorities. The present study usesthe theory of acculturation to explain the selection of ethnic and mainstream brands by the South Asian ethnic minority in the UK and assumes that the level of influences the brand selection. The study assumes that the consumers with a high level of acculturation tend to buy the mainstream brands; on the contrary, the consumers with a low level of acculturation tend to buy the ethnic brands. The study uses the acculturation taxonomy developed by Berry (1997) and extents on the consumer acculturation by exploring the role of acculturation in brand choices.

In general, various demographic factors are used to explain consumer behaviour. Therefore, variables like age, gender, income, etc. are considered important determinants of consumer behaviour (e.g. Solomon, Russell-Bennett and Previte, 2012). This study extends on the consumer behaviour theory by testing the personal demographics (age, income, gender and length of stay in the UK) and acculturationto explore the brand choices of South Asian ethnic minorities in the UK.

The Britain has seen changing population demographics over the last 60 years with the arrival of individuals from countries which formerly comprised the British Empire. Due the sizable proportion of ethnic minorities, it is important for the marketing professionals understand the consumer behaviour of these ethnic minorities. Emslie, et al. (2007) clearly refer this market segment is a "missing opportunity" for marketers. According to the National statistics of the UK (ONS, 2011), the resident population of the UK was $63,182,178$, the White share of the population was $92 \%$, (National census 2001). It has reduced to $87 \%$ in the census 2011 due to the increase in the ethnic minority share in the population. The increase in ethnic minority population representing a variety of sub-cultural groups such as Indians, Pakistani, Bangladeshis, Chinese, Black-Caribbean, Irish, Poles, Central European Jews, Cypriots, Turks and more recently Kosovons, and Albanians (Jamal, 2003). Census statistics of 2011 revealed that the South Asians are the single largest ethnic group in the UK comprising of around 50\% of total non-white population in the UK (ONS, 2015). Because of their size, the study of consumer behaviour of the South Asian immigrants is worth investigating.

This research study is about the brand choices of ethnic minorities in the UK, particularly focussed on Asian and British Asians. There are many studies about these ethnic minorities regarding acculturation of ethnic minorities and Marketing to these minorities. This study attempts to explore the influence of acculturation on the consumer behaviour. The current research uses the Acculturation framework developed by John Berry and his colleagues, to 
explore the level of adaptability of the South Asians to the mainstream population and its influence on the selection of ethnic (South Asian) and mainstream (UK) brands.

The study develops a model of ethnic minority consumer behaviour and uses a quantitative methodology to test the model. This study will adopt the acculturation measure developed by Cleveland et al. (2009) as the basis for measuring acculturation. This measure divides acculturation into five major dimensions, including cultural identity, family roles, language preferences, media use and social Interactions. Structural Equation modelling will be used to explain the influence of acculturation and demographics on the brand choices.

\section{RESEARCH OBJECTIVES}

The present study explores the brand choice of the immigrant consumers from the South Asian countries living in the UK. The main objective of the study is to expound role of acculturation in selecting the home and host country brands. The home country brands are those who are marketed by the companies located and based in the south Asian countries. While the mainstream brands are the brands that were established in the UK. The objective of the study can be framed as follows:

This study investigates that what role varying degree of acculturation plays in determining the brand choice of the South Asian immigrants in the UK.

Based upon the above discussionthefollowing research questions were framed to explain the relationship between acculturation and the brand choice.

1. Whether the mainstream brand choices increase with the increasing level of acculturation in the Asian and British Asian consumers living in the UK?

2. Whether the ethnic brand choices increase with the decreasing level of acculturation in the Asian and British Asian consumers living in the UK?

3. Whether the ethnic and mainstream brand choices increase with the medium level of acculturation in the Asian and British Asian consumers living in the UK?

To conduct this study, it is important to explain how to measure the level of acculturation, as well as what various brands will be selected.

This study contributes in the marketing by empirically examining the level of acculturation of the South Asian population. Since, the South Asia consists of India, Pakistan, Bangladesh, Sri Lanka, Nepal and Bhutan, this study also explores the acculturation gaps amongst these countries. Above all, this study tests the Social identity theory and its applicability on consumer behaviour.

\section{LITERATURE REVIEW}

Study of immigrant behaviour is theorized by social scientists in the US, to explain the process how newcomers in America become incorporated into mainstream culture (Padilla and Perez, 2003). As America is a country of immigrants, immigrant behaviour research remained popular there for a long time, starting from University of Chicago "Melting Pot" theorists to modern acculturation process theories. Robert Redfield et al. (1936) define acculturation as ". . . those phenomena which result when groups of individuals having different cultures come into continuous first-hand contact, with subsequent changes in the original cultural patterns of either or both groups".

Behavioural changes may occur in host culture, or the immigrants or both, in general acculturation influence is not much significant in mainstream culture (Berry 1997), rather it 
influences more on the individuals coming from different cultures. They need to adapt to the host culture is higher, as the people from host culture are larger in number. Moreover, they dominate the resources of society (Ogden et al., 2004).

America puts serious efforts to assimilate immigrants in the early 1900 . Immigrants were asked to learn the language of adopted country as quickly as possible and country puts serious efforts to Americanize new immigrants (Williamson et al., 1910). Contrary to this recent trends show that the new immigrants have no much desire to assimilate fully. Cleveland and Laroche (2007) used a term "hyper identification" with the culture or origin, and they referred "Mexican immigrants in the U.S. consuming greater quantities of foodstuffs associated with Mexico, than do Mexicans in their home country". But it does not negate the concept of acculturation fully. Food stuff consumption is one example; there are many areas in which new immigrant assimilate, in many cases it is important for their survival. At individual and group level cultural contact, conflict and adaptation are the major issues of acculturation study (Berry, 1980). The nature of cultural contact, its purpose and duration can vary significantly from one individual to the other and it can influence the acculturation process.

Oberg (1960 cited in Penaloza, 1989) studied cultural change in missionaries and presented several stages of this change. These stages include Honeymoon stage, Rejection stage, tolerance stage and Integration stage. In the early phase of cultural contact with the new culture fascinates the immigrants, as the contact is superficial, so cultural adaptation does not exist. On the rejection stage, new entrants start disliking the new culture and he or she tries to get along with the people from the culture of origin. In the third stage, immigrants acquire some cultural skills and knowledge. Conflict starts losing its intensity and tolerance starts increasing. At integration stage, starts viewing the new culture as another way of life and there is an adequate level of cultural adjustment. As the study was conducted for missionaries who may be more resistant to cultural change as their motive is converting belief system of the natives (Penaloza, 1989), the immigrants who arrive in a country without such mission may be more adaptive to the new culture, as in the case of the general consumer. So it may be worth of inquiry to look for consumer acculturation.

The following hypotheses were framed based upon the literature:

H1: A high level of acculturation in the South Asian minority consumers in the UK positively influences the purchase of mainstream brands.

$\mathrm{H} 2$ : The high level of acculturation in the South Asian minority consumers in the UK negatively influences the purchase of South Asian brands.

H3: The Length of stay in the host country positively influences the level of acculturation of the South Asian minority consumers in the UK.

H4: The age negatively influences the level of acculturation of the South Asian minority consumers in the UK.

H5: The income of immigrants positively influences the level of acculturation of the South Asian minority consumers in the UK.

H6: The gender (male) positively influences the level of acculturation of the South Asian minority consumers in the UK. 


\subsection{Acculturation and consumer behaviour}

Acculturation is the process of learning and adopting some of the cultural patterns of the country of residence (Rajagopalan and Heitmeyer 2005). When immigrants come to country of establishment or host country, they experience socio-cultural system that is different from their home country or country of origin. The immigrants get used to the system over time. Researchers have also found that various ethnic groups not only differ in the extent to which they acculturate to the host society. Members within an ethnic group also vary in their levels of acculturation (Youn-Kyung Kim, Kang, 2001).

In consumer acculturation literature, there are two basic waves, one deals with assessing migrants consumption patterns, and the other deals with exploring cultural experiences of migrants (Luedicke 2011). According to Berry $(1997,1980)$ migrants adopt various strategies to acculturate depending upon their attitude towards home culture and the host culture. These strategies are assimilation, integration, segregation, or marginalization. As far as consumer acculturation is concerned, marketing literature focuses on the acculturation through consumption (Lindquist 1974). Consumer acculturation scholars Wallendorf and Reilly (1983) and Desphande, et al. (1986) established the field of "consumer acculturation research" by determining the degree of cultural assimilation through distinguished consumption choices vis-a -vis mainstream culture. Penaloza (1994, 1989) Oswald (1999) and Askegaard, Arnould, and Kjeldgaard (2005) instead of sequential assimilation presented "Postassmilationist" view and quoted that acculturation process significantly depends upon migrants' economic, social and cultural circumstances.

\section{RESEARCH METHODOLOGY}

Level of acculturation was measured using a scale developed by the scale adapted from (Cleveland et al., 2009) was used to measure the extent of behavioural acculturation o. This scale was found it highly reliable with a Cronbach alpha correlation of 0.97 (ibid). To measure the degree of acculturation variables like language consumer speak at home, with friends, books and magazines they read, the music they listen, places they go, recreation they do. A number of South Asian and Mainstream brtish barnds were selected for the brand preference. The list of ethnic and mainstream brands for the various brands in the product categories are presented in the table 1.

The data can be collected through the various means in the quantitative studies, for example face to face interview, postal questionnaire, telephone interview, etc. To collect attitude related information, survey design is the most suitable technique to collect data (Bryman and Bell, 2015).

In the absesnce of any population list, a cinvieneint sampling technique was used. Using the existing theoretical/practical guidelines for selecting an adequate sample size, a sample of 390 was decided as prescribed by Krejcie and Morgan (1970).An SEM (structural equation modelling) technique will be used to analyse the data. This technique is useful in ensuring the reliability and validity of data. The hypothesis testing will be used with the help of structural model as per the criteria set by Hair et al. (2006). 
Table 1: List of ethnic and mainstream brands

\begin{tabular}{|c|c|c|}
\hline Product Category & Ethnic Brand & Mainstream Brand \\
\hline Food Products & $\begin{array}{l}\text { KTC Cooking oil } \\
\text { Rubicon Juice } \\
\text { Tilda Rice }\end{array}$ & $\begin{array}{l}\text { Flora Cooking Oil } \\
\text { Ribena Juice } \\
\text { Uncle Ben's Rice }\end{array}$ \\
\hline Entertainment Brands & $\begin{array}{l}\text { Bollywood } \\
\text { Star TV }\end{array}$ & $\begin{array}{l}\text { Hollywood } \\
\text { ITV }\end{array}$ \\
\hline Travel Service Brands & $\begin{array}{l}\text { PIA/Indian Airline } \\
\text { Southall Travels }\end{array}$ & $\begin{array}{l}\text { British Airways } \\
\text { Thompson Travels }\end{array}$ \\
\hline Telecommunication Brands & Labara Mobile/Lyca Mobile & Vodafone/T Mobile \\
\hline
\end{tabular}

\subsection{Data analysis, Results and Findings}

The data exhibits that acculturation has strong significant positive relationship with British brands; on the contrary, it has strong negative relationship with the South Asian brands. The relationship between the British and South Asian brands is significant and negative. Similarly, other relationships in the model are moderate to strong and significant. The table suggests the further analysis to explore the extent of influence through the beta coefficients may be meaningful. However, to proceed further, it is important to ensure the reliability and validity of the data and measures testing the variables, particularly acculturation.

The level of acculturation of the South Asians living in the UK was measured with the help of five dimensions. The table 2 provides a brief overview of the acculturation dimensions, and the selection of brands. To create this table, first of all the mean value of each dimension was calculated for the each respondent, as well as for the brand selection. The values were incorporated in the data table by creating a new variable for each component.

\subsection{Reliability and Validity}

The acculturation was a major focus of study; therefore, it was important to ensure the reliability of the various scale items measuring acculturation. The Cronbach's Alpha was calculated for the each dimension measuring acculturation. The alpha value in this case was .70 for these 20 variables. This exceeds the .70 , so this represents a reasonable level of internal consistency, according to the criterion described by Nunnally (1978).

It was proposed initially that total eight brands in each category of the ethnic and non-ethnic brands will be used. According to Cudeck (2000), in many cases the items are correlated with each other, which mean that scores on each variable share some information contained by the others. Therefore, to overcome his problem, EFA or exploratory factor analysis may be a wise choice. The objective EFA is to quantify the level to which each variable is associated with the other factors in the model. The most commonly used method is the Kaiser greater than 1 criterion (K1), which retains factors with eigenvalues greater than 1 (Kaiser, 1960).

The figure 1 exhibits the structural model, with the variables in the study and their respective unstandardised regression weights. In the structural model five dimensions determining the level of acculturation were used. This model, then seeks to explain the influence of acculturation on the selection of ethnic and non-ethnic brands. Then this study attempted to analyse the influence of LOS, age, income, and gender on acculturation.

Tong \& Bentler (2013) suggested using the maximum likelihood estimation procedure to test various research hypotheses through SEM. The table 2 exhibits the standardised and 
unstandardised parameter estimates, standard error and the p-values for the hypothesised paths of the model. In the notes of table 2, the model fitness estimates are also presented. The model measures the direct relationships between personal characteristics and acculturations, as well as acculturation and the brand choice. The results have indicated that the model provides an acceptable level fit to the data (CMIN/DF, 5.65, NFI $=0.92$, CFI 0.91, while RMSEA $=0.067$ ). The fitness indices are evaluated according to the criteria suggested by $\mathrm{Hu}$ and Bentler (1999).

\subsection{Acculturation purchase of brands}

It was hypothesised in the H1, that high level of acculturation in the South Asian minority consumers in the UK positively influences the purchase of mainstream brands. As revealed in the table 2, the beta value for this relationship is positive and it is significant; therefore, it can be inferred that the level of acculturation positively influence the selection of mainstream brands. The results obtained through this study are in the line of the previous study Vijaygopal and Dibb (2012), who found that the more acculturated individuals from the Indian origin prefer mainstream brands over the ethnic brands. Therefore, based upon the results from the data analysis it can be inferred that South Asian immigrants who adapt to the culture of the mainstream white population in the UK also adapt to using the mainstream British brands.

The hypothesis 2 states that, high level of acculturation in the South Asian minority consumers in the UK negatively influences the purchase of South Asian brands. The results are in accordance with the expectations. The table 2 exhibits that beta coefficient for this relationship is negative and it is significant; therefore, it can be inferred that the level of acculturation negatively influences South Asian brand choice.

Table 2: The standardised and unstandardised parameter estimates

\begin{tabular}{|c|c|c|c|c|c|c|c|}
\hline & & Unsta & dardize & & Standa & rdized & \\
\hline $\begin{array}{l}\text { Predicted } \\
\text { Construct }\end{array}$ & Predictor Construct & $\beta$ & SE & $\mathrm{p}$ & $\beta$ & SE & $\mathrm{p}$ \\
\hline $\begin{array}{l}\text { Non-Ethnic } \\
\text { Acculturation }\end{array}$ & Brands <--- & 3.67 & 0.059 & 0.00 & .885 & 0.015 & 0.00 \\
\hline $\begin{array}{l}\text { Ethnic Brands } \\
\text { Acculturation }\end{array}$ & $<---$ & -1.23 & 0.028 & 0.00 & -.699 & 0.014 & 0.00 \\
\hline Acculturation & $<---\quad$ LOS & .046 & 0.03 & 0.01 & 0.146 & 0.026 & 0.01 \\
\hline Acculturation & $<---\quad$ AGE & -.201 & 0.03 & 0.00 & -0.270 & 0.027 & 0.00 \\
\hline Acculturation & $<---\quad$ INCOME & 0.047 & 0.03 & 0.00 & 0.301 & 0.029 & 0.00 \\
\hline $\begin{array}{l}\text { Acculturation } \\
\text { (MALE) }\end{array}$ & $<---\quad$ GENDER & -.05 & 0.07 & 0.10 & -0.076 & 0.02 & 0.10 \\
\hline
\end{tabular}

\subsection{Length of stay and Acculturation}

The hypothesis 3 states that, the Length of stay in the host country positively influences the level of acculturation of the South Asian minority consumers in the UK. Therefore, it assumes that longer a person stays in the host country, more acculturated he or she will be. The table 2 exhibits that the beta value for this relationship is positive and it is 
significant; therefore, it can be inferred that the length of stay positively influences the level of acculturation. The results are consistent with the existing literature Berry (1997), Penaloza (1994) and Miglietta \& Tartaglia, (2009). Schwartz et al. (2010) however, found that for those immigrants who live in the ethnic enclaves the length of stay may not be an influence on acculturation.

\subsection{Age and Acculturation}

The hypothesis 4 states that, the age negatively influences the level of acculturation of the South Asian minority consumers in the UK. Therefore, it assumes that with the increasing age, acculturation goes down. The table 2 exhibits that the beta value for this relationship is negative and it is significant; therefore, it can be inferred that the age negatively influence the level of acculturation. The result is in support of the proposed hypothesis. The results are consistent with the past studies, for example, Jamal (1998) who found that the youngster exhibit higher level of adaptation to the host culture values. Similar results were found Cleveland et al. (2009)

\subsection{Income and Acculturation}

The hypothesis 5 states that the income of immigrants positively influences the level of acculturation of the South Asian minority consumers in the UK. Therefore, it assumes that with the increasing income the level of acculturation increases. The table 2 exhibits that the beta value for this relationship is positive and it is significant; therefore, the data provide sufficient evidence to infer that the income positively influence the level of acculturation. The existing evidence also suggests that income has a positive influence on acculturation; see Üstüner and Holt (2010) and Cleveland et al. (2009).

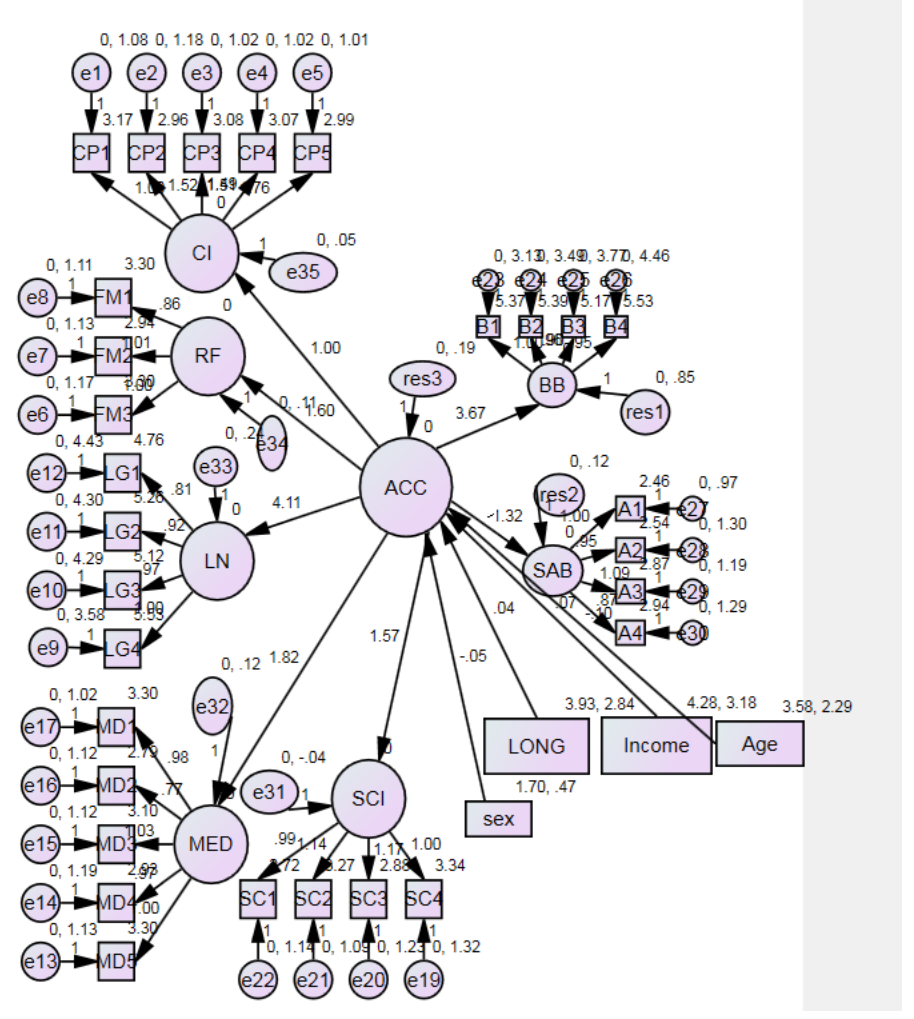

Figure 1: Structural Model for testing 


\subsection{Gender and Acculturation}

The hypothesis 6 states that, the gender (male) positively influences the level of acculturation of the South Asian minority consumers in the UK. Therefore, it assumes that with the male immigrants are more acculturated than their counterpart. The table 2 exhibits that the beta value for this relationship is negative and it is not significant at $5 \%$ confidence level; therefore, it can be inferred the data failed to provide support for the relationship between gender and the level of acculturation. Thus the result is not in support of the proposed hypothesis.

\section{FINDINGS AND DISCUSSION}

The issue of acculturation is an important factor for the social scientists and the marketing practitioners due to increasing migration pressures. Economic disparities and wars have triggered the phenomenon. The immigrants, when they migrate also bring their home country's cultural baggage with them. In some cases immigrants adapt to the host country culture, in some other case, they prefer to maintain their home country culture. Though it is believed that, in most of the cases, the immigrants have to adapt to the host country culture. However, the evidence also suggests that in some cases, immigrants may exhibit "hyperidentification" to their home culture (Cleveland, et al 2015, Hsu, 2013). For example, it may be referred as, "Indians in the UK are more Indians than the Indians in India".

The studies on acculturation in the past, has a limited focus on the acculturation process itself. A scant literature was developed to explore the influence of acculturation on consumption and behaviour. This study was conducted targeting the South Asian immigrants in the UK, who formulate the largest ethnic minority group in the UK. They also have distinct cultural characteristics, for example, they are more collectivist and high on masculinity than most of the British (see: Hofstede, 1994). This study uses explores to what extent the acculturation influences the brands choice. Since acculturation is a latent variable, and it is difficult for the marketing people to develop a consumer profile based upon acculturation, therefore four personal characteristics were incorporated, to test their influence on the acculturation. These characteristics include length of stay in the host country, age, income, and gender. The personal characteristics are more observable and marketing professionals can develop appropriate marketing strategies to target the market segments within immigrant population.

\subsection{Acculturation and Brand choice}

It is explained in the earlier that culture plays an important role in consumer behaviour. For consumers, selecting a particular brand may be important, since the brand can also be used for the projection of self. For the minority consumers, who remained exposed to certain products and brands while in their home country; after migration, the brand selection may or may not vary. In some cases, brands that represent the home country may be used to satisfy the "nostalgia", or to express their home country culture.

This study used eight British and ethnic brands, to observe the how acculturation influences the brand choice. It was found the level acculturation strongly influences the brand choices of the South Asian immigrants in the UK. The data revealed that, acculturation positively influences the selection of mainstream brands. On the contrary, the level of acculturation has negative influence on the selection of ethnic brands. Based upon the evidence collected in this research, it can be further argued that adapting to the British or the host culture, results in changing brand choices. 


\subsection{Personal demographics and acculturation}

The present study explores role of different personal demographic factors influencing the level of acculturation in the South Asian minority population in the UK. Some of the factors may have a positive influence on the level of acculturation; on the other hand, some factors may slow down the acculturation. This study has adopted length of stay, age, income and gender as personal demographic factors.

The data revealed that length of stay and income positively influences acculturation. That, longer a person stays in the UK, more adapted he or she will be to the home culture. The length of stay may have implications for the second generation of immigrants. Since they were born in the UK and have longer contact with the host country culture, therefore, the second generation South Asians may be more acculturated. However, the study does not measure this influence directly. A further discussion on this particular issue is explained in the section of limitations. Similarly, immigrants with the high income are more adapted to the host culture, while people with low income tend to remain practice the culture of their home country. People with little income have less economic capital to participate in the host country culture. Age was found to be a negative influence the level of acculturation in the south Asian minority population in the UK. The data failed to provide significant evidence to support the positive influence of male gender on the acculturation. Therefore, I can be argued that, acculturation pattern does not vary amongst male and female population of the immigrants. While, the length of stay, age and income are more relevant characteristics in determining the adaptation to host country culture.

\section{RECOMMENDATIONS}

The findings of the present research may provide some useful insight for the marketing practitioners in the UK to help targeting them the ethnic minority consumers. The business potential of the ethnic minority consumers in the UK cannot be ignored by businesses any longer. These minority populations, including the South Asians, Polish, and Africans have substantial importance. They represent large market segments, as well as, they have a substantial growth (ONS, 2011). According to a report in The Telegraph (2013), "Third of children born in England has foreign-born parent". Based upon the data this study suggests marketers should not ignore the minority consumers and develop appropriate strategies to attract them.

From the recommendations' point of view, the high acculturated minority consumer population may not present any challenge, because they can be attracted through broad marketing strategies for the mainstream population. However, attracting the low acculturated consumers will require a separate marketing plan. The following section presents some guidelines for the retail and media marketing professionals.

The retail marketing professionals should have an ethnic merchandise section in their retail stores to attract their ethnic customers. Though it is observable that the food-based retailers do provide ethnic products in the world food section. However, the assortment is limited to the food items only. While the retailers may ignore other product categories, for example, entertainments, communication or leisure products. In order to buy the ethnic brands, customers have to visit small shop, mostly referred as "off Licence." These retailers charge a high price due to their business inefficiencies. Retailers like, TESCO, ASDA, to offer a real time one-stop shopping, should offer a wider range of ethnic brands to attract their low acculturated customers. With the help of national statistics, it is relatively simple to estimate 
the ethnic profile a particular area. Therefore, the retailers can offer ethnic brands in the ethnically concentrated neighbourhoods.

The results may have implications for the marketing communication professionals to develop message strategy and media strategy. To attract ethnic minority customers with low acculturation, they should develop a message appeal that is relevant to their ethnic audiences, as well as, the endorser. Similarly, the communication professionals should be sensitive about using the appropriate media vehicle for their low acculturated customers.

\section{LIMITATIONS AND FUTURE RESEARCH}

It is almost impossible to conduct a research without any limitations or biases, this study is not an exception. The findings from this study must be interpreted within the set limitations to the study. This survey was conducted online, and the questionnaire was sent to the respondents with the help of various religious and professional groups. The most of the respondents were members of these organizations. Therefore, the sample may present a high level of home culture orientation be default. A more non-biased random technique may be followed to recruit the respondents.

The study uses the length of stay as an antecedent to acculturation and completely ignores the role of generational status. Since, the children of immigrants, or the second-generation immigrants, who were born in the UK, may have contact with the culture from their childhood. The role of length of stay may not be relevant to them. Therefore, a separate variable, e.g. Generational status can be added in the future studies.

The study scope was cross-sectional; therefore, the findings are drawn upon the basis of the current status of acculturation of the respondents. Other research designs, like longitudinal design, may explain the influence of acculturation on the brand choice in a more appropriate way.

\section{REFERENCES}

Armstrong, D. and Haiss, P., (2007). Ethnic Banking: Identifying The Capacity And Future Implications of The Ethnic Banking Market, Oxford Business \& Economics Conference 2007

Arnould, E.J. and Thompson, C.J., (2015) Introduction: Consumer Culture Theory: Ten Years Gone (and Beyond). Consumer Culture Theory (Research in Consumer Behavior, Volume 17) Emerald Group Publishing Limited, Vol.17, pp.1-21.

Askegaard, S., Arnould, E.J. and Kjeldgaard, D., (2005). Postassimilationist Ethnic Consumer Research: Qualifications and Extensions. Journal of Consumer Research, Vol. 32(1), pp. 160-170.

Bryman, A. and Bell, E., (2015). Business research methods. Oxford University Press, USA.

Cleveland, M. And Laroche, M., (2007). Acculturation to the global consumer culture: Scale development and research paradigm. Journal of Business Research, Vol. 60(3), pp. 249259.

Cleveland, M., Laroche, M. and Papadopoulos, N., (2015). You are what you speak? Globalization, multilingualism, consumer dispositions and consumption. Journal of Business Research, Vol. 68(3), pp.542-552.

Cleveland, M., Laroche, M., Pons, F. and Kastoun, R., (2009). Acculturation and consumption: Textures of cultural adaptation. International Journal of Intercultural Relations, Vol. 33(3), pp.196-212. 
Cudeck, R., (2000). Exploratory factor analysis. Handbook of applied multivariate statistics and mathematical modeling, pp.265-296.

De Mooij, M., (2013). Global marketing and advertising: Understanding cultural paradoxes. Sage Publications.

De Mooij, M., (2015). Cross-cultural research in international marketing: clearing up some of the confusion. International Marketing Review, Vol. 32(6), pp.646-662.

Deshpande, R., Hoyer, W.D. and Donthu, N., (1986). The Intensity of Ethnic Affiliation: A Study of the Sociology of Hispanic Consumption. Journal of Consumer Research, Vol. 13(2), pp. 214-220.

Hair, J. F., Black, W. C., Babin, B. J., Anderson, R. E., \& Tatham, R. L. (2006). Multivariate data analysis (Vol. 6). Upper Saddle River, NJ: Pearson Prentice Hall.

Hofstede, G., (1994). The business of international business is culture. International business review, Vol. 3(1), pp.1-14.

Hu, L.T. and Bentler, P.M., (1999). Cutoff criteria for fit indexes in covariance structure analysis: Conventional criteria versus new alternatives. Structural equation modeling: a multidisciplinary journal, Vol. 6(1), pp.1-55.

Jamal, A. (2003). Marketing in a multicultural world: The interplay of marketing, ethnicity and consumption. European Journal of Marketing, Vol. 37(11/12), 1599-1620.

Jamal, A., (1998). Food consumption among ethnic minorities: the case of British-Pakistanis in Bradford, UK. British Food Journal, Vol. 100(5), pp. 221-227.

Jobber, D. and Ellis-Chadwick, F., (2012). Principles and practice of marketing (No. 7th). McGraw-Hill Higher Education.

Kaiser, H. F. (1960). The application of electronic computers to factor analysis. Educational and psychological measurement.

Krejcie, R.V. and Morgan, D.W., (1970). Determining sample size for research activities. Educ psychol meas.

Luedicke, M.K., (2011). Consumer acculturation theory: (crossing) conceptual boundaries. Consumption, Markets \& Culture, Vol. 14(3), pp. 223-244.

Miglietta, A. and Tartaglia, S., (2009). The influence of length of stay, linguistic competence, and media exposure in immigrants' adaptation. Cross-Cultural Research, Vol. 43(1), pp.46-61.

Mokhlis, S., Nik Hazimah, N.M. And Salleh, H.S., (2010). Ethnicity and Choice Criteria in Retail Banking: A Malaysian Perspective. International Journal of Business \& Management, Vol. 5(6), pp. 98-105.

Nunnally, J.C., (1975). Psychometric theory. 25 Years ago and now. Educational Researcher, Vol. 4(10), pp.7-21.

Ogden, D T., James R. Ogden, And Hope J S , (2004). Exploring the Impact of Culture and Acculturation on Consumer Purchase Decisions: Toward a Microcultural Perspective. Academy of Marketing Science Review, 2004, pp. 1.

ONS, (2015). Office of National Statitics, Nomis Tools Accessed online.

Oswald, L.R., (1999). Culture Swapping: Consumption and the Ethnogenesis of MiddleClass Haitian Immigrants. Journal of Consumer Research, Vol. 25(4), pp. 303-318.

Penaloza, L. and Gilly, M.C., (1999. Marketer Acculturation: The Changer and the Changed. Journal of Marketing, Vol. 63(3), pp. 84-104.

Penaloza, L., N., (1989). Immigrant consumer Acculturation. Advances in Consumer Research, Vol. 16, pp. 110-118.

Solomon, M., Russell-Bennett, R. and Previte, J., (2012). Consumer behaviour. Pearson Higher Education AU.

Solomon, M.R., (2014). Consumer behavior: buying, having, and being. Engelwood Cliffs, NJ: Prentice Hall. 
Tong, X. and Bentler, P.M., (2013). Evaluation of a new mean scaled and moment adjusted test statistic for SEM. Structural equation modeling: a multidisciplinary journal, Vol. 20(1), pp.148-156.

Vijaygopal, R. and Dibb, S., (2012). Exploring the role of acculturation in brand choice: A new perspective for targeting Indians living in the United Kingdom. Journal of Targeting, Measurement and Analysis for Marketing, Vol. 20(1), pp.47-56.

Visconti, L.M., Jafari, A., Batat, W., Broeckerhoff, A., Dedeoglu, A.Ö., Demangeot, C., Kipnis, E., Lindridge, A., Peñaloza, L., Pullig, C. and Regany, F., (2014). Consumer ethnicity three decades after: A TCR agenda. Journal of Marketing Management, Vol. 30(17-18), pp.1882-1922.

Wallendorf, M. and Reilly, M.D., (1983). Ethnic migration, assimilation, and consumption. Journal of Consumer Research, pp.292-302. 